Article

\title{
Environmental Information-Explanatory Factors for Information Behavior
}

\section{Chris von Borgstede * and Kristin Andersson}

Department of Psychology, Gothenburg University, P.O. Box 500, Haraldsgatan 1, SE 40530, Gothenburg, Sweden; E-Mail: kristinandersson@yahoo.se

* Author to whom correspondence should be addressed; E-Mail: cvb@psy.gu.se; Tel.: +46-31-786-4260; Fax: +46-31-786-4628.

Received: 15 July 2010; in revised form: 15 August 2010 / Accepted: 25 August 2010 / Published: 2 September 2010

\begin{abstract}
As sustainable waste management has become an important environmental concern, growing emphasis is being given to policy tools aimed at increasing recycling behavior by households. Information is a common policy tool, but may not always reach the individuals whose behavior is being targeted, i.e., those reluctant to recycle. This study examined individual differences in attention to recycling information and demand for such information. A nationwide survey in Sweden showed that having personal norms for recycling is important when it comes to obeying and seeking environmentally relevant information. In contrast to earlier research, this study found that lack of information alone is not a significant antecedent to the intention to seek information. Personal norms were found to moderate the effect of perceived lack of information on the intention to seek information.
\end{abstract}

Keywords: information behavior; attention; recycling information; personal norms

\section{Introduction}

Disproportionate solid waste production is a serious problem in modern societies, and sustainable management has therefore become an important concern for governments [1]. Recycling can reduce the amount of waste that goes to incineration or landfills, as well as reducing energy use and emissions generated, bringing environmental and economic benefits [2]. Along with the development of technical solutions, policy measures promoting individuals to recycle are critically important. Information is a 
widespread policy measure aimed at increasing environmental concern, awareness about environmental problems and (for example) participation in recycling programs. Depending on the source and message, information as a policy tool can be an effective way to spread knowledge about new systems of waste handling, facilities and the recycling procedure. Information also has the potential to persuade, creating positive attitudes towards the recycling system among the public $[3,4]$. Problem awareness has been shown to be an important antecedent for pro-environmental behavioral intentions and behavior [5-9]. This problem awareness could be activated by information, and an improved knowledge about the problem. However, it has been questioned whether improved knowledge and positive attitudes are successful ways of changing actual behavior [10,11]. According to Martinez and Scicchitano [12], the use of mass media information can be effective within limits, but the effectiveness is partly due to the "design" of the message. An effective message is suggested to take motivational factors as well as possible barriers for changing the behavior into account [10,13-15].

Another question addressed here is whether mass media information could actually pass by without attention from recipients and consequently without being processed or taken into account. For example, implementation of a recycling program must often be accompanied by sufficient information and promotion in order to make householders aware about how and when to use it. Informational promotions may make use of various media such as leaflets delivered to households or announcements in the local press or radio. Though leaflet drops or adverts in the local press are among the cheapest ways to administer policy tools as information, it has been questioned whether their message is even received or understood [16]. Despite extensive publicity over many years for the kerbside recycling program in England, many residents claimed to have seen none, which supports the argument that information in terms of leaflet drops are often regarded as junk mail [17]. Thus, the persuasive impact of information depends not only on factors associated with the information (e.g., the type and structure of arguments), but also on the recipient's attention and cognitive processing of the information, as well as individual factors. These individual factors include socio-demographic variables such as age, gender and education, as well as psychological variables such as attitudes, values and beliefs, and they can all impact how a message is attended to and how persuasive it is [18]. Apart from difficulties arising in reaching the target group of the information, more general education and information to give a broader picture of waste management are required in order to apprise the public of the necessity of sustainable waste management. This study addresses individual differences in relation to two aspects of information behavior, namely attention and information seeking.

\subsection{Information Behavior}

This study examines information behavior, which is an "umbrella term" that includes, among others, perceiving and processing information, as well as actively seeking information [18]. Information processing has perhaps been the most commonly researched information behavior in psychology, e.g., [3,19-22]. Previous research on information processing typically attempts to explain the different steps and ways in which information is processed and how it affects attitudes [20]. Another field of research has examined information seeking [23], focusing on motivational factors and antecedents to seek information, e.g., [23-25]. Overall, there is a need among policy makers to acknowledge that the ability to comprehend, accept and process information may vary between individuals. It can therefore 
be assumed that there are individual differences with regard to how information is comprehended and sought, in respect to a policy tool. Previous research has been dominated by studying information behavior regarding product information (e.g., consumer information; [21]) and information regarding health (e.g., health information-seeking; [26]). Less attention has been given to behaviors associated with information regarding the environment. It can be assumed that reactions toward environmental information, such as recycling information, differ from reactions toward information regarding consumer products [10]. Environmental information often appeals to self-sacrificing actions and, in contrast to health information, it contains information about impersonal risk rather than personal risk [27]. There is thus a need to study information behavior specifically in relation to environmental information.

By recognizing individual differences in regard to responses to information, recycling information campaigns may be designed to reach even those people who are less likely to attend to, or seek, recycling information.

\subsection{Information Attention}

In accordance with early information processing research, McGuire [21] proposed a behavioral "chain of responses" comprising six steps in an attempt to understand information processing [21]. The argument was that omission of any of these six information processing steps would cause the sequence to be broken, so that subsequent steps would not occur. Attention is one of the early steps in McGuire's paradigm, as it is essential for further processing of the information and, in turn, whether the message has any impact on the recipient's attitudes or behavior [20,21]. According to the information-processing paradigm proposed by McGuire, the recipient must be presented messages in a suitable way and, given that exposure occurs, the recipient must pay attention to the message in order for it to produce attitude change. Today, most of us are exposed to a vast amount of information, in many different forms, but only a fraction of the information is processed. People tend to engage in information that comforts and agrees with their own ideas and avoid information that contradicts their opinion or that does not seem relevant to them. This phenomenon has been described in terms of selective exposure [28]. Both attention and exposure have been more or less operationalized in similar ways in previous research. However, while exposure has been measured as individuals' preferences for exposing themselves to different information, attention should be regarded as a more passive process of perception [20]. There are individual factors associated with how information is selectively attended to, e.g., socio-demographical factors such as age, gender, education and lifestyle correlate with attention to information [18]. Moreover, factors associated with attention to information can also be psychological in the sense that they relate to a person's beliefs and attitudes. It has been recognized that people are more likely to notice information that is relevant for their current goals. In addition, it is widely accepted that people attend to information that agrees with the attitudes they already hold $[20,28,29]$. At the same time, there is a tendency for people to prefer information that confirms their preconceptions or hypotheses, regardless of whether it is true or not [30]. Therefore, it is reasonable to assume that people with strong positive environmental attitudes will pay attention to information about environmental protection to a greater extent than those who have neutral or ambivalent environmental attitudes. 


\subsection{Information Seeking}

Information seeking is a conscious, energetic way of acquiring information [22]. Compared with attention, information seeking can be viewed as a more active and directed behavior [31]. Analysis of information-seeking behavior is worthwhile, since recipients must primarily pay attention to a persuasive message in order to generate an attitude change [20]. In research on information-seeking behavior, people are assumed to search for information when they experience a lack of knowledge [22]. However, beliefs about one's own capacity to gather information have been found to have a moderating effect on information seeking [27].

Furthermore, people sometimes avoid information despite feeling a lack of knowledge [32], again illustrating that more intervening factors need to be identified. Beliefs about the topic concerned and personal goals in relation to that topic could be additional factors to explore in relation to information seeking. If people are presented with information that they think is relevant for them, they may also seek information with the intention of making appropriate decisions. For example, changes in the surroundings world can induce a sense of personal relevance and by that have an effect on information seeking. A possible influence of changes in circumstances such as critical incidents (e.g., the ultimate up-to-date oil leak outside the Mexican Gulf) could therefore serve as a stimulating factor for information attention and seeking. Other factors found to be significant in predicting information seeking include a notion of normative social pressure to be informed [33].

\subsection{Norms}

Previous studies have concluded that norms constitute a strong motive for environmental behavior [34,35]. A norm is generally defined as an expectation held by an individual about how he or she ought to act in a particular social situation [36]. The norm provides an impetus for proper behavior and the individual need not deliberate about consequences. Norms can further be divided into two groups, one at the societal level, that is social norms, and one at the personal level, personal norms. In general, personal norms are social norms that have been internalized and have become a part of a person's conscience. The essential distinguishing factor between social norms and personal norms is where the threat of sanctions or the promise of rewards comes from. Such sanctions or rewards can be administered by other people in a social group (social norms) or by the actor her- or himself (personal norms). In short, sanctions and rewards can come from outside or from within [37].

Social norms are further divided into descriptive and prescriptive norms, each referring to a separate source of human motivation [38]. The descriptive norm describes what is typical or normal behavior in a specific situation. A descriptive norm can offer an information-processing advantage and a decisional shortcut when people choose how to behave in a particular situation [38]. A prescriptive or injunctive norm specifies what people ought to do; how people in the same culture or society ought to act to preserve everybody's best interest. It refers to rules or beliefs as to what constitutes morally approved or disapproved conduct.

Research in environmental psychology has stressed the role of personal norms as personal moral obligations (e.g., "what I ought to do") in environmental behavior, perhaps even more predominantly when it comes to recycling [39-42]. Personal norms are specific personal guidelines for appropriate behavior and may either be internalized social norms or norms derived from higher order values [36]. 
However, results regarding the unique influence of social norms on recycling are mixed and indirect [42], whereas personal norms are directly related to recycling behavior $[40,43,44]$. Consequently, the effect of personal norms appears to be stronger than the effect of social norms, especially on recycling $[42,45]$. In addition, some studies show that social norms influence behavior only via personal norms [40], see also $[41,44,46]$. If the behavior involves self-sacrifice, personal norms serve as a reminder of values important to the individual $[35,47]$, which may help overcome the barrier to high-cost recycling. In addition, personal norms to take pro-environmental action are generally activated by beliefs that environmental conditions are threatened. One aim of the present study was to investigate whether personal norms have a moderating effect on information-seeking behavior, e.g., whether in order to be willing to attend to and seek environmentally relevant information it is necessary to have more specific problem awareness, namely that recycling can be an important contribution to reducing environmental problems. Therefore, personal norms can be assumed to also influence information behavior in relation to recycling information.

\subsection{The Present Study}

In this study, we examined the antecedents of attention to information on recycling. In particular, we investigated how demographic factors (gender, education and type of dwelling) and psychological factors (environmental concern and personal norm) affect attention to information. The primary aim was to identify factors that can improve the likelihood of information being attended to.

A second aim was to examine factors that can predict seeking of recycling information. Here, we used the intention to seek information as the dependent variable. We hypothesized that lack of information as well as personal norms and an intention to change behavior can predict an individual's intention to seek information. In addition, we expected personal norms to moderate the relationship between lack of information and the intention to seek information (see Figure 1). This relationship (as an interaction term) was tested by a hierarchical regression model.

Figure 1. Hypothesized model of information seeking intention.

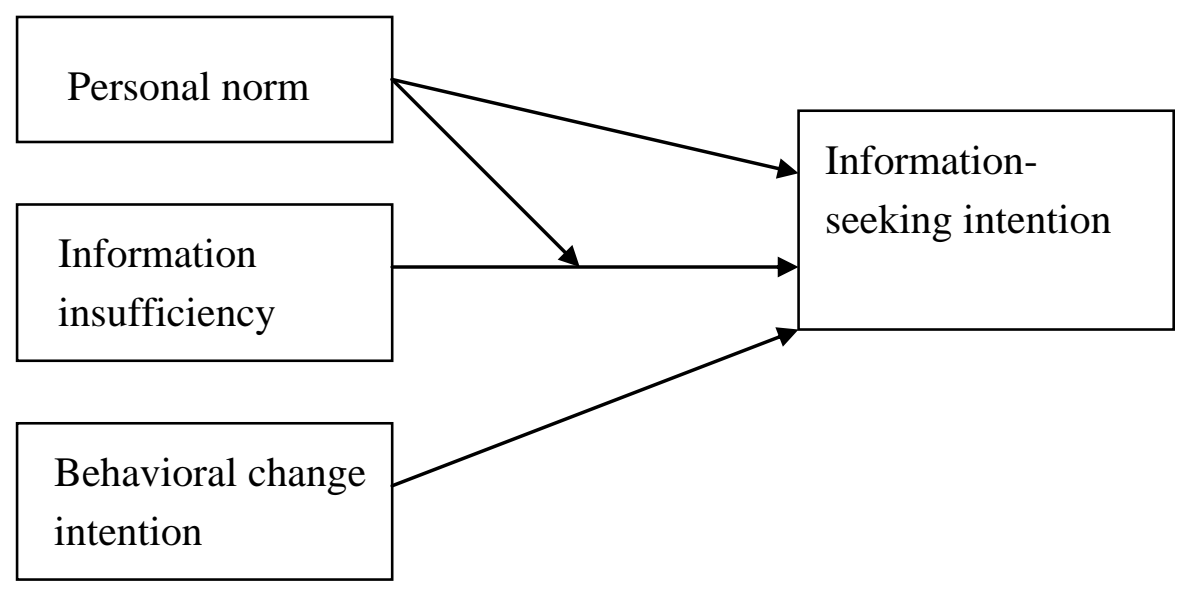




\section{Method}

\subsection{Sample and Procedure}

A postal questionnaire was administered to 1,000 randomly selected respondents aged 20-65 years living in Sweden. A lower age limit was set in order to avoid adolescences that still live at their parents' home and an upper limit was set in order to comprise respondents that are not yet retired from work. The questionnaire was sent out in two batches during the months of May and June 2007. Each batch included a cover letter, a copy of the questionnaire and a pre-paid return envelope. In addition, all respondents were sent a combined reminder and thank you card. After these two reminders, the total response rate was $48 \%(\mathrm{~N}=430)$. Usable questionnaires from 418 respondents were included in subsequent analyses. The mean age of the respondents was 45 years and gender distribution included $44.5 \%$ men. Approximately one-third of the respondents had a university degree.

\subsection{Questionnaire}

In the introduction to the questionnaire, respondents were informed about the overall purpose of the study, which was to investigate people's thoughts and behavior in relation to source separation of waste. The focus was mainly on the respondents' current knowledge about waste separation, and on their motives for recycling or their reasons for not doing so. Attitudes, norms and self-reported behavior were also measured and there were questions tapping beliefs and behavior regarding recycling information. The questionnaire consisted of seven parts, three of which are analyzed here, namely attitudes, norms and knowledge about recycling behavior. Questions about background characteristics (age, education, type of dwelling and gender) concluded the questionnaire.

\subsection{Measures}

Information attention. The dependent variable was measured by asking respondents if "they had paid attention to any information regarding waste separation or recycling during the past month". Initially, answers were given on a 3-point scale consisting of 1 (several times); 2 (sometimes) and 3 (not at all). The variable was then recoded into a dichotomous variable of noticed (1-2); or not noticed (3).

Information-seeking intention. The second dependent measure was measured by a single statement: "I am prepared to search for more information in order to sort more of my household waste". Answers were given on a 7-point Likert scale ranging from 1 (strongly disagree) to 7 (strongly agree).

Lack of information. This was measured by asking the respondents whether they believed they had sufficient knowledge about what to recycle; whether they perceive a lack of information. Answers were given as one of three options: no, uncertain and yes.

Behavior change intention. This was measured by the statement: "I plan to recycle more of my waste in the coming year". Answers were given on a 7-point scale ranging from 1 (strongly disagree) to 7 (strongly agree).

Each subsequent construct, i.e., personal norm and environmental concern, was derived from a principal component analysis (PCA) with Varimax rotation. 
Personal norm. PCA on the statements capturing the normative component resulted in a one-factor solution. Answers to the statements included were all given on a 7-point Likert scale ranging from 1 (strongly disagree) to 7 (strongly agree).

The items "I believe I have a personal responsibility to recycle my waste", "I feel a personal obligation to contribute to environmentally friendly waste separation", "I would react negatively if I discovered that waste that could have been recycled had been disposed of in the wrong place", and "I feel bad if I don't recycle my waste" formed a factor labeled personal norms $(\alpha=0.84)$.

Environmental concern. This factor appeared from the PCA and included the following items: "Environmental issues are important and should receive more attention", "It is important that we do what we can to minimize the load on the environment", "I am prepared to lower my standard of living if necessary to protect the environment", "It takes a lot of effort to act in an environmental friendly manner" (reversed) and "Too much tax money is devoted to environmental protection" (reversed). Ratings of the items included were all given on a 7-point Likert scale ranging from 1 (strongly disagree) to 7 (strongly agree). The factor was labeled environmental concern $(\alpha=0.70)$.

For the demographic variables, gender was coded as " $0=$ man" and " $1=$ woman"; education was re-coded into three groups: 1 = statutory schooling, $2=$ higher schooling and $3=$ college or above. Finally, type of dwelling was coded as living in a flat (0) or in a house (1).

\subsection{Data Analysis}

Analyses were carried out in two parts. In the first part, a binary logistic regression was conducted to test three demographic variables (gender, education and type of dwelling) and two psychological variables (environmental concern and personal norm for recycling) for the dependent variable attention of information.

In the second part, information seeking (a continuous variable) was used as the dependent variable and a multiple regression was performed to test the model proposed for information-seeking intention. Lack of information, personal norm and behavior change intention were used as independent variables.

\section{Results}

\subsection{Attention to Recycling Information}

A logistic regression was performed with information attention as the binary dependent variable. Type of dwelling, gender, education, environmental concern and personal norm were used as predictor variables. A total of 397 cases were analyzed and the full model was found to be statistically reliable (chi-square 13.37, df = 5, p < 0.05). The model accounted for between $3.3 \%$ and $4.5 \%$ of the variance in information attention. Personal norm, type of dwelling and gender were all significantly associated with paying attention to information. Those who felt a normative obligation to recycle were more likely to have noticed the information, as were women, and those living in a house rather than in a flat. Table 1 gives the Wald statistic and associated degrees of freedom and probability values for each predictor variable. The model correctly predicted the attention to information for $63.6 \%$ of respondents, $27.3 \%$ of those who had not paid attention to any information and $84.4 \%$ of those who had paid attention to information. 
Table 1. Logistic regression of information attention *.

\begin{tabular}{ccccc}
\hline Predictor & $\begin{array}{c}\text { Regression } \\
\text { Coefficient }\end{array}$ & SE & Wald & P \\
\hline Type of dwelling & 0.493 & 0.366 & 3.20 & 0.023 \\
Gender & -0.463 & 0.376 & 2.33 & 0.033 \\
Education & 0.049 & 0.256 & 0.35 & 0.748 \\
Environmental concern & -0.097 & 0.245 & 0.67 & 0.483 \\
Personal norm & 0.202 & 0.180 & 3.42 & 0.039 \\
\hline
\end{tabular}

Note: *Dependent variable coded $0=$ have not noticed information; 1 = have noticed information.

\subsection{Intention to Seek Information}

In the second part, a hierarchical regression analysis was performed in order to test the predictability of lack of information, behavior change intention and personal norm on information-seeking intention. When questionnaires with missing data (on the variables included in the analysis) were removed from the analyses, 408 questionnaires remained and were included in the analysis.

Table 2 shows the means, standard deviations and product-moment correlations between the items and indices. As expected, the means were near the middle of the scale, except for personal norm, which had a slightly higher mean. The correlations were all non-significant.

Table 2. Mean values (M), standard deviation (SD) and Pearson product moment correlations among the variables in the hierarchical regression.

\begin{tabular}{lcccccc}
\hline & $M$ & $S D$ & 1 & 2 & 3 & 4 \\
\hline 1 Intention to seek information & 4.19 & 1.67 & - & & & \\
2 Lack of information & 1.73 & 0.81 & -0.043 & - & & \\
3 Behaivor change intention & 3.70 & 2.11 & 0.176 & 0.117 & - & \\
4 Personal norm & 5.31 & 1.32 & 0.349 & -0.066 & 0.092 & - \\
\hline
\end{tabular}

Note: All measures range from 1 to 7 , except lack of information that ranges from 1 to 3.

A hierarchical regression was performed in order to examine the model (see Figure 1) for prediction of intention to seek information. In a first step, three predictors were added: intention to recycle more waste, personal norm and lack of information. This model was statistically significant, $F(3,402)=22.5, \mathrm{p}<0.001, \mathrm{R}^{2}=0.144$. As shown in Table 3, personal norm and intention to recycle more both had a significant effect, while lack of information was not a significant predictor. Since the hierarchical regression included an interaction term, all variables were standardized.

The interaction variable was entered in a second step. The interaction variable coded for the interaction between lack of information and personal norm. The addition of this variable significantly increased the model; $F(4,401)=4.16, \mathrm{p}=0.042, \mathrm{R}_{\text {adj }}^{2}=0.009$. The resulting model was significantly greater than zero, $F(4,401)=18.1, \mathrm{p}<0.001, \mathrm{R}^{2}=0.153$.

The relationship between lack of information and intention to seek information was not a straightforward linear main effect. Only when lack of information interacted with personal norm did it 
influence the intention to seek information. As the data show, lack of information had an effect on information-seeking intention only for those who felt a personal obligation (personal norm) to recycle.

Table 3. Results of the hierarchical regression analysis of intention to seek information.

\begin{tabular}{cccc}
\hline Model & Predictor & $\beta$ & $p$ \\
\hline 1 & Lack of information & -0.039 & 0.405 \\
& Personal norm & 0.331 & 0.000 \\
& Intention to recycle more & 0.150 & 0.001 \\
\hline 2 & Lack of information & -0.035 & 0.448 \\
& Personal norm & 0.337 & 0.000 \\
& Intention to recycle more & 0.144 & 0.002 \\
& Interaction & 0.094 & 0.042 \\
\hline
\end{tabular}

\section{Discussion}

The main purpose of this paper was to examine individual differences in relation to information behavior. This was done by exploring attention to information and seeking of information. The study first proposed and tested different factors influencing individual information attention. The data obtained supported the predicted relationship between personal norms and readiness to pay attention to environment-related information, suggesting that a personal norm, which signifies what the individual ought to do in relation to recycling, framed information attention. This result is partly in accordance with the view presented by [47-49] positing that values direct attention toward value-congruent information, resulting in an increased general awareness of environmental problems. The results in the present study suggest that personal norms could have the same influence. Although the factors included in the logistic regression could only account for a small proportion of the variance in information attention, those factors that were not statistically significant are of theoretical interest. Level of education was not a significant predictor, signifying that lack of formal education is not a barrier to information attention. Environmental concern was also unrelated to attention to information. This result contradicts earlier findings that people are biased towards information consistent with their attitudes [50]. Confirmation bias is a cognitive bias, whereby people tend to notice and look for information that confirms their existing beliefs, whilst ignoring anything that contradicts those beliefs. It is thus a type of selective thinking. However, the present study found that having a positive attitude to environmental issues did not explain attention to environmentally relevant information.

A general awareness concerning environmental problems as threats to the biosphere and humankind did not influence the level of information attention. Having general awareness of the problem was thus shown to be important for generating problem awareness concerning a specific situation, in this case unsorted waste as a cause of environmental problems and the seriousness of these waste-induced problems.

The second part of the analysis used intention to seek for information as a dependent variable, and here too the personal norm was an important predictor. As well as being related to the intention to seek information, the personal norm was an important moderator of the effect of lack of information on intention to seek information. 
Taken together, these findings may have practical implications for information seeking, as information insufficiency (here: lack of information) has often been seen as the main motivator for information-seeking behavior. People with neutral or negative attitudes to sorting household waste may not perceive that they lack knowledge - they may feel they are well-informed but suspicious about the necessity or effectiveness of recycling. If this is the case, a possible solution is to frame environmental information differently in order to reach those who hold neutral or negative attitudes toward environmental issues. By exploring the antecedents of attention to recycling information, we can find indications why some information fails to reach the target audience.

Moreover, the results showed that a personal intention to change behavior had a significant effect on the intention to seek information, assuming that information will be sought only when it is relevant for current goals. A practical conclusion is that people holding personal norms favoring recycling are more prone to search for environmental information. This calls for a rethink about how different kinds of information are channeled. Furthermore, considering household waste management (where people put their household waste) a habitual behavior, with little or no reasoning or planning required, recycling information aimed at changing attitudes will probably pass by without any notice from recipients. However, when establishing new environmentally friendly habits, e.g., from not separating waste to separating, the model of habit change proposes that different kinds of information are more useful in different phases of behavior change [51]. A prerequisite for changing a habit is to be aware of current behavior and know that there are alternative ways. For example, Biel et al. [51] argue that changing a habitual behavior into a new stable habit progresses through several steps, where each step generates a need for different kinds of support. As a consequence, different kinds of information are needed in diverse phases. People who have internalized social norms into personal norms can be assumed to be in the latter stages of behavior change and feedback information can motivate them to continue with the behavior. Thus recycling information provided e.g., on internet sites should focus less on creating stronger positive attitudes (and for that reason probably easily processed messages, which in turn may promote the use of heuristics) and more on giving positive feedback. Since those who find the information here are more likely to already be recycling, information on how local goals for source separation are being met (descriptive social norms) as well as on the environmental benefits (effectiveness) can give further motivation.

Previous studies suggest that an effective design of the kerbside intervention scheme, by up-following public consultation and gradual introduction of kerbside recycling into targeted areas with a "high quality communications campaign", the degree of "satisfaction" with the information about the kerbside scheme was highly improved [52-54]. Not only satisfaction with the information campaign has been reported. It has also been claimed that a communications campaign had strongly "influenced" individuals to recycle more, and that newsletters were the most effective communications method. By recognizing the central role of a quality communications strategy in delivering high participation rates in kerbside collection schemes, research has shown the importance to a dedicated communication with a plethora of different communication strategies [55].

A weakness in the present study was that by using the survey method we were not able to check for any differences in the amount and type of information the participants had been presented with or accessed. Overall, further research is needed to understand how people with different levels of waste separation behavior and in different phases of habitual change respond to different types of 
information in different media. In regard to the representativeness of the sample in this study, a few notions are worth mentioning here. It should be clear that a sample of 1,000 is not a guarantee of its ability to accurately represent a target population. A survey sample's ability to represent a population has in large to do with the sampling frame: that is the list from which the sample is selected. Selection bias is a risk when some parts of the target population are not included in the sampled population. However, the sample in this study is recruited by a Swedish company that is specialized in information management and responsible for the operation of the so called SPAR database and by that it guarantees the randomly selected sample. We ordered a randomized sample with an age criteria that was set between 20 and 65 in order to minimize the possibility of inclusion of adolescents who still live with their parents and to only include people that still work and are healthy enough to live at their own home, in order to ensure the representativeness.

The take-home message here would be that by communicating different kinds of information that can reach different target groups, there is a greater chance of influencing behavior and attaining better sustainability in waste management.

\section{Acknowledgements}

This research was financially supported by a grant from the Swedish Environmental Protection Agency to the program "Research towards sustainable waste management". Thanks are due to Anders Biel and Maria Andersson for constructive comments.

\section{References}

1. Skräp hit och dit—på vinst och förlust (Waste to and from—at a venture). In Formas Fokuserar; The Swedish Research Council Formas: Stockholm, Sweden, 2004.

2. Björklund, A.E.; Finnveden, G. Life cycle assessment of a national policy proposal-The case of a Swedish waste incineration tax. Waste Manage. 2007, 27, 1046-1058.

3. Petty, R.E.; Cacioppo, J.T. Communication and Persuasion: Central and Peripheral Routes to Attitude Change; Springer-Verlag: New York, NY, USA, 1986.

4. Bator, R.J.; Cialdini, R.B. The application of persuasion theory to the development of effective proenvironmental public service announcements. J. Soc. Issue. 2000, 56, 527-541.

5. Stern, P.C.; Dietz, T.; Black, J.S. Support for environmental protection: The role of moral norms. Pop. Environ. 1985, 8, 204-222.

6. Newhouse, N. Implications of attitude and behavior research for environmental conservation. J. Environ. Edu. 1990, 22, 26-32.

7. Klandermans, B. Persuasive communication: Measures to overcome real-life social dilemmas. In Social Dilemmas: Theoretical Issues and Research Findings; Liebrand, W.B.G., Messick, D.M., Wilke, H.A.M., Eds.; Pergamon: Oxford, UK, 1992; pp. 307-318.

8. Grob, A. A structural model of environmental attitudes and behavior. J. Environ. Psychol. 1995, 15, 209-220.

9. Stern, P.C. Toward a coherent theory of environmentally significant behavior. J. Soc. Issue. 2000, $56,407-424$. 
10. McKenzie-Mohr, D. Promoting sustainable behavior: An introduction to community based social marketing. J. Soc. Issue. 2000, 56, 543-554.

11. Schultz, W.P. Knowledge, information, and household recycling: Examining the knowledge-deficit model of behavior change. In New Tools for Environmental Protection: Education, Information and Voluntary Measures; Dietz, T., Ed.; National Academic Press: Washington, DC, USA, 2002; pp. 67-82.

12. Martinez, M.D.; Scicchitano, M.J. Who listens to trash talk? Education and public media effects on recycling behavior. Soc. Sci. Quar. 1998, 79, 287-300.

13. Barr, S.; Gilg, A. Sustainable lifestyles: Framing environmental action in and around the home. Geoforum 2006, 37, 906-920.

14. Mee, N.; Clewes, D. The influence of corporate communication on recycling behaviour. Corp. Commun. 2004, 9, 265-275.

15. Stern, P.C. Information, incentives and proenvironmental consumer behavior. J. Consum. Policy 1999, 22, 461-478.

16. Martin, M.; Williams, I.D.; Clark, M. Social, cultural and structural influences on household waste recycling: A case study. Resour. Conserv. Recycl. 2006, 48, 357-395.

17. Read, A. A weekly doorstep recycling collection, "I had no idea we could!" Overcoming the local barriers to participation. Resour. Conserv. Recycl. 1999, 26, 217-249.

18. McGuire, W.J. Theoretical foundations of campaigns. In Public Communication Campaigns; Rice, R., Atkin, C., Eds.; Sage: Newberry Park, CA, USA, 1989; pp. 43-65.

19. Chaiken, S.; Trope, Y. Dual-Process Theories in Social Psychology; Guildford Press: London, UK, 1999.

20. Eagly, A.; Chaiken, S. The Psychology of Attitudes; Harcourt Brace: Orlando, FL, USA, 1993.

21. McGuire, W.J. Some internal psychological factors influencing consumer choice. J. Consum. Res. 1976, 2, 302-319.

22. von Borgstede, C.; Andersson, M. Value-related information processing: An experimental study on waste prevention. 2010, (in preparation).

23. Case, D.O. Looking for Information: A Survey of Research on Information Seeking, Needs, and Behavior; Elsevier: Amsterdam, The Netherlands, 2007.

24. Johnson, J.D. Cancer Related Information Seeking; Hampton Press: Cresskill, NJ, USA, 1997.

25. Wilson, T.D. Models in information behaviour research. J. Doc. 1999, 55, 249-270.

26. Lamberth, S.D.; Loiselle, C.G. Health information-seeking behavior. Qual. Health Res. 2007, 17, 1006-1019.

27. Kahlor, L.; Dunwoody, S.; Griffin, R.J.; Neuwirth, K. Seeking and processing information about impersonal risk. Sci. Commun. 2006, 28, 163-194.

28. Frey, D. Recent research on selective exposure to information. In Advances in Experimental Social Psychology; Berkowitz, L., Ed.; Academic Press: New York, NY, USA, 1986; Volume 19, pp. 41-80.

29. Festinger, L. A Theory of Cognitive Dissonance; Stanford University Press: Stanford, CA, USA, 1957. 
30. Lewicka, M. Confirmation Bias: Cognitive Error or Adaptive Strategy of Action Control? In Personal Control in Action: Cognitive and Motivational Mechanisms; Kofta, M., Weary, G., Sedek, G., Eds.; Springer: Dordrecht, The Nederlands, 1998; pp. 233-255.

31. Bates, M. Toward an Integrated Model of Information Seeking and Searching. In Proceedings of The Fourth International Conference on Information Needs, Seeking and Use in Different Contexts, Lisbon, Portugal, 11-13 September 2002.

32. Case, D.O.; Andrews, J.E.; Johnson, J.D.; Allard, S.L. Avoiding versus seeking: The relationship of information seeking to avoidance, blunting, coping, dissonance, and related concepts. J. Med. Libr. Assn. 2005, 93, 353-362.

33. Griffin, R.J.; Dunwoody, S.; Neuwirth, K. Proposed model of the relationship of risk information seeking and processing to the development of preventative behaviours. Environ. Res. Sect. A 1999, 80, 230-245.

34. Biel, A.; von Borgstede, C.; Dahlstrand, U. Norm perception and cooperation in large-scale social dilemmas. In Resolving Social Dilemmas: Dynamic, Structural, and Intergroup Aspects; Foddy, M., Smithson, M., Schneider, S., Hogg, M., Eds.; Psychology Press: Philadelphia, PA, USA, 1999; pp. 245-252.

35. Biel, A.; Thøgersen, J. Activation of social norms in social dilemmas: A review of the evidence and reflections on the implications for environmental behaviour. J. Environ. Psychol. 2007, 28, 93-112.

36. Schwartz, S.H. Normative influence on altruism. In Advances in Experimental Social Psychology; Berkowitz, L., Ed.; Academic Press: New York, NY, USA, 1977; pp. 221-279.

37. Kerr, N.L.; Garst, J.; Lewandowski, D.A.; Harris, S.E. That still, small voice: Commitment to cooperate as an internalized versus social norm. Pers. Soc. Psychol. Bull. 1997, 23, 1300-1311.

38. Cialdini, R.B.; Reno, R.R.; Kallgren, C.A. A focus theory of normative conduct: Recycling the concept of norms to reduce littering in public places. J. Pers. Soc. Psychol. 1990, 58, 1015-1026.

39. Andersson, M.; von Borgstede, C. Differentiation of determinants of low-cost and high-cost recycling. J. Environ. Psychol. 2010, (in press).

40. Bratt, C. The impact of norms and assumed consequences on recycling behavior. Environ. Behav. 1999, 31, 630-656.

41. Hopper, J.R.; Nielsen, J.M. Recycling as altruistic behavior: Normative and behavioral strategies to expand participation in community recycling programs. Environ. Behav. 1991, 23, 195-220.

42. Thøgersen, J. Recycling and morality: A critical review of the literature. Environ. Behav. 1996, 28, 536-558.

43. Davies, J.; Foxall, G.R.; Pallister, J. Beyond the intention-behaviour mythology: An integrated model of recycling. Market. Theory 2002, 2, 29-114.

44. Do Valle, P.O.; Reis, E.; Menezes, J.; Rebelo, E. Behavioral determinants of household recycling participation, environment and behavior. Environ. Behav. 2004, 36, 505-540.

45. Thøgersen, J. Monetary incentives and recycling: Behavioural and psychological reactions to a performance-dependent garbage fee. J. Consum. Policy 2003, 26, 197-228.

46. Stern, P.C.; Dietz, T.; Guagnano, G.A.; Kalof, L. A value-belief-norm theory of support for social movements: The case of environmentalism. Res. Hum. Ecol. 1999, 6, 81-97. 
47. Harland, P.; Staats, H.; Wilke, A.M. Situational and personality factors as direct or personal norm mediated predictors of pro-environmental behavior: Questions derived from norm-activation theory. Basic Appl. Soc. Psych. 2007, 29, 323-334.

48. Stern, P.C.; Dietz, T. The value basis of environmental concern. J. Soc. Issue. 1994, 50, 65-84.

49. Stern, P.C.; Dietz, T.; Kalof, L.; Guagnano, G.A. Values, beliefs and pro-environmental action: Attitude formation toward emergent attitude objects. J. Appl. Soc. Psychol. 1995, 25, 1611-1636.

50 Baron, J. Thinking and Deciding, 3rd ed.; Cambridge University Press: New York, NY, USA, 2000.

51. Biel, A.; Dahlstrand, U.; Grankvist, G. Habitual and value-guided purchase behavior. Ambio 2005, 34, 360-365.

52. Thomas, C. Public understanding and its effect on recycling performance in Hampshire and Milton Keynes. Resour. Conserv. Recycl. 2001, 32, 259-274.

53. Evison, T.; Read, A.D. Local authority recycling and waste awareness publicity/promotion. Resour. Conserv. Recycl. 2001, 32, 275-292.

54. McDonald, S.; Oates, C.J. Reasons for non-participation in a kerbside recycling scheme. Resour. Conserv. Recycl. 2003, 39, 369-385.

55. Mee, N.; Clewes, D.; Phillips, P.S.; Read, A.D. Effective implementation of a marketing communications strategy for kerbside recycling: A case study from Rushcliffe, UK. Resour. Conserv. Recycl. 2004, 42, 1-26.

(C) 2010 by the authors; licensee MDPI, Basel, Switzerland. This article is an open access article distributed under the terms and conditions of the Creative Commons Attribution license (http://creativecommons.org/licenses/by/3.0/). 